\title{
Prediction of Peritoneal Cancer Index and Prognosis in Peritoneal Metastasis of Gastric Cancer Using NLR-PLR-DDI Score: A Retrospective Study
}

\author{
Zeyao Ye* \\ Pengfei Yu* \\ Yang Cao \\ Tengjiao Chai \\ Sha Huang \\ Xiangdong Cheng \\ Yian Du
}

Department of Gastric Surgery, The Cancer Hospital of the University of Chinese Academy of Sciences (Zhejiang Cancer Hospital), Institute of Basic Medicine and Cancer (IBMC), Chinese Academy of Sciences, Hangzhou, Zhejiang, 310022, People's Republic of China

*These authors contributed equally to this work

Correspondence: Yian Du;

Xiangdong Cheng

Department of Gastric Surgery, The Cancer Hospital of the University of Chinese Academy of Sciences (Zhejiang Cancer Hospital), Institute of Basic Medicine and Cancer (IBMC), Chinese Academy of Sciences, Hangzhou,

Zhejiang, 3 I0022, People's Republic of China

Tel +86-57I-88I2804I

Email duyajim@I26.com;

abdsurg@163.com
Objective: The peritoneal cancer index (PCI) is used to evaluate the peritoneal metastasis of gastric cancer. A higher value indicates more widespread and/or larger tumors in the peritoneal cavity. The neutrophil-lymphocyte ratio (NLR) and platelet-lymphocyte ratio (PLR) are representative blood markers of systemic inflammatory responses, and D-dimer (DDI) is the final stable product of fibrin. This study explores the association of NLR, PLR, and DDI with PCI and assesses the clinical utility of a new blood score combining the NLR, PLR, and DDI (NPD score) for PCI and the prognosis prediction of gastric cancer.

Methods: This was a single-center, nonrandomized, retrospective, cohort study. We evaluated the risk factors for high PCI $(\geq 15)$ using univariate and multivariate analyses. According to the findings of the ROC analysis, we determined the cut-off values of NLR, PLR and DDI and created the NPD score. The patients were grouped into high-risk and low-risk groups based on their NPD score $(<2$ and $\geq 2$, respectively).

Results: Univariate and multivariate analysis demonstrated that the NLR, PLR, and DDI were independent risk factors for high PCI $(\mathrm{P}<0.05)$. The NPD score of the highrisk group was $\geq 2$, and the NPD score of the low-risk group was $<2$. The median survival time was 14.2 in the high-risk group and 25.6 in the low-risk group. The NPD score was significantly higher in the high-PCI group than that in the low-PCI group. The survival of the high-risk group was significantly worse than that of the low-risk group $(\mathrm{P}=0.003)$. NPD score decrease was an independent predictive factor for PCI decrease.

Conclusion: NLR, PLR, and DDI are potential independent risk factors for high PCI in patients with peritoneal metastasis of gastric cancer. The NPD scoring system can help in predicting PCI and the prognosis of patients with peritoneal metastasis of gastric cancer.

Keywords: gastric cancer, peritoneal metastasis, peritoneal cancer index, PCI, NLR-PLRDDI score, prognosis

\section{Introduction}

Gastric cancer is one of the most common gastrointestinal malignancies and the third leading cause of cancer-related mortality worldwide. ${ }^{1}$ Peritoneal metastasis is often responsible for treatment failure in gastric cancer. It has been reported that approximately $60 \%$ of gastric cancer patients eventually die from peritoneal dissemination. $^{2,3}$ Once peritoneal metastasis begins, refractory ascites, intestinal 
obstruction, and cachexia may appear, which are the main causes of death in patients with advanced gastric cancer. ${ }^{4}$ Peritoneal dissemination has a poor prognosis irrespective of whether the disease is at the initial, progression, or recurrent stage. Noninvasive, sensitive, and specific biomarkers are required to determine peritoneal dissemination. Traditional imaging techniques such as computed tomography (CT) and magnetic resonance imaging (MRI) are not sensitive enough for the detection and evaluation of peritoneal metastasis. Therefore, diagnostic staging laparoscopy (DSL) is performed to confirm the diagnosis and extent of peritoneal metastasis. ${ }^{5}$ The peritoneal cancer index (PCI) is a useful tool to assess disease extensity and can help in determining the prognosis and operability of peritoneal metastasis. ${ }^{6,7}$ This classification system divides the abdomen into nine sectors and the small bowel into four additional sectors. The lesion size score for each sector is summed up to determine the total score (Figure 1). ${ }^{7}$

The systemic inflammatory response is closely related to the progression of malignant tumors, including gastric cancer. ${ }^{8,9}$ The neutrophil-to-lymphocyte ratio (NLR) and platelet-to lymphocyte ratio (PLR) are important hematological biomarkers and can be used as significant prognostic markers in several neoplasms, including gastric cancer. ${ }^{10-13}$ D-dimer (DDI), a degradation product of fibrin, is produced when cross-linked fibrin is degraded by plasmin-induced fibrinolytic activity. ${ }^{14}$ In a study on 1178 patients over a 2-year period, Ay et al found that in a subgroup of 50 gastric cancer patients, increased DDI plasma levels were associated with reduced survival and were a significant risk factor for mortality. ${ }^{15}$
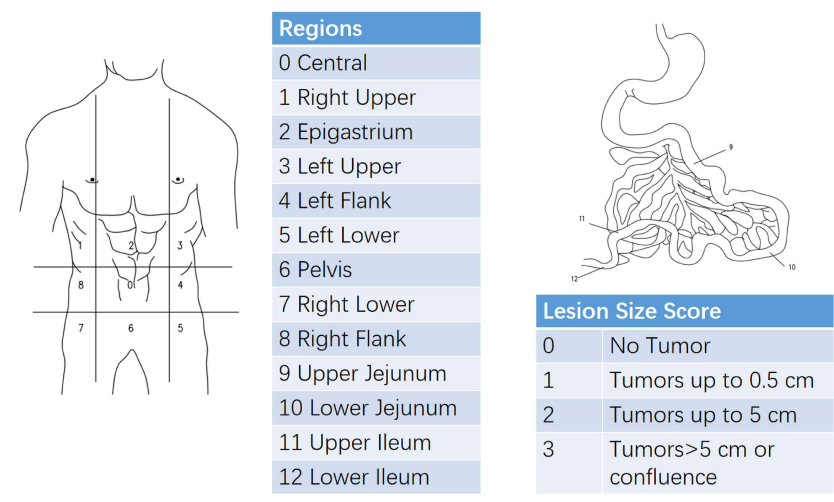

Figure I Peritoneal Cancer Index (PCI) scoring system. ${ }^{7}$ Notes:Data from Tabrizian et al.
High pretreatment plasma-DDI levels are also a predictive marker of poor prognosis in gastrointestinal tumors. ${ }^{16}$

However, the diagnostic role of NLR, PLR, and DDI has not been clarified in patients with peritoneal metastasis of gastric cancer, although it is generally believed that biomarker combinations might have a better diagnostic value than individual markers. In the present study, NLR, PLR, and DDI in patients who underwent DSL were investigated for PCI scoring. An NPD scoring system was also created to predict PCI and determine prognosis in the peritoneal metastasis of gastric cancer.

\section{Methods}

\section{Patients}

This is a nonrandomized retrospective cohort study. In this study, 114 patients with peritoneal metastasis of gastric cancer who underwent DSL for PCI scoring between September 2015 and May 2021 at Zhejiang Cancer Hospital, Hangzhou, China, were retrospectively enrolled. The following inclusion criteria were used: (1) advanced gastric cancer, suspected peritoneal metastasis, including ascites, omental metastasis, or ovarian metastasis; (2) positive peritoneal cytology or peritoneal dissemination confirmed by DSL; and (3) absence of other distant metastases. The following exclusion criteria were used: (1) severe intraperitoneal adhesions, resulting in the failure of PCI scoring. (2) prior treatment (radiotherapy, chemotherapy, targeted therapy, or immunotherapy); (3) presence of a synchronous or metachronous malignancy; (4) prior hematologic disorders; (5) presence of definite infection for 2 weeks; and (6) previous gastrectomy. Finally, 102 patients (55 men and 47 women; age range, 28-82 years; mean age, 57.6 years) were included in the present study.

\section{$\mathrm{PCl}$}

All 102 patients completed DSL and PCI scoring (PCI range, 0-36; mean PCI, 11.66). The patients were categorized into low-PCI $(\mathrm{PCI}<15)$ and high-PCI $(\mathrm{PCI} \geq 15)$ groups. ${ }^{17}$ With the exception of one patient who refused further treatment, all patients received systemic chemotherapy and hyperthermic intraperitoneal chemotherapy (HIPEC). After HIPEC and 4 cycles of neoadjuvant systemic chemotherapy, a second laparoscopic exploration was performed for 41 patients (PCI range, 0-39; mean PCI, 5.17). 


\section{Laboratory Tests}

Laboratory tests, including a complete blood count, biochemistry, DDI, tumor markers, and blood coagulation test, were conducted before performing DSL for all patients. A laboratory examination was performed before the second laparoscopic exploration as well. The NLR was determined as the neutrophil count divided by the lymphocyte count, while the PLR was determined as the platelet count divided by the lymphocyte count.

\section{Statistical Analysis}

The Statistical Package for Social Sciences (SPSS ver.26.0 SPSS Inc., Chicago, IL, USA) was employed for data analysis. The Student's $t$-test and the chi-square test were performed to compare continuous and discrete variables, respectively. Wilcoxon signed rank test was used to compare abnormal distribution variables. Logistic regression analysis was used to identify risk factors for high PCI. Receiver operating characteristic (ROC) curves were constructed, and the areas under the curves (AUCs) were calculated to evaluate the predictive abilities of the NLR, PLR, and DDI for discriminating patients with high PCI from those with low PCI. The relationships between the NPD score and PCI/prognosis were assessed using the chi-square test. Survival was analyzed using Kaplan-Meier curves. Prognostic factors were assessed using univariate and multivariate analyses (Cox proportional hazard regression model). A P-value of $<0.05$ was considered statistically significant.

\section{Results}

\section{Patient Characteristics}

There were four patients with positive peritoneal lavage cytology (CY1) and 98 with peritoneal metastasis, including 52 with $\mathrm{CY} 1$ and 20 with ovarian metastasis. The mean initial PCI was $11.66 \pm 8.20$ (range 0-36). Based on the initial PCI (PCI $<15$ or not), the patients were divided into low-PCI $(\mathrm{n}=67)$ and high-PCI $(\mathrm{n}=35)$ groups. Differentiation, NLR, PLR, DDI, and the levels of tumor markers in the two groups were compared (Table 1).

The median NLR values for the low-PCI and highPCI groups were $2.72 \pm 2.45$ and $4.33 \pm 5.52$, respectively, with a statistically significant difference $(\mathrm{P}=$ 0.001). The median PLR values were $187.3 \pm 90.51$ and $236.0 \pm 163.06$, respectively; the difference was statistically significant $(\mathrm{P}=0.007)$. The median DDI values were $237.0 \pm 733.31$ and $779.0 \pm 1212.57$, respectively, and the difference was statistically significant $(\mathrm{P}=0.001)$. The median $\mathrm{CA} 125$ values were 35.3 \pm 170.6 and $134.0 \pm 154.5$, respectively, and the difference was statistically significant $(P=0.001)$ (Table 1$)$.

\section{Univariate and Multivariate Analyses of High PCl}

Univariate analysis demonstrated that NLR, PLR, DDI, and cancer antigen 125 (CA125) were associated with high PCI ( $\geq 15)$, while gender, age, body mass index (BMI), differentiation, and serum levels of carcinoembryonic antigen (CEA), CA199, and alpha-fetoprotein (AFP) had no marked impact. Multivariate analysis showed that NLR (odds ratio $(\mathrm{OR})=1.276,95 \% \mathrm{CI}$ $1.051-1.550 ; \mathrm{P}=0.014)$, PLR $(\mathrm{OR}=1.006 ; 95 \% \mathrm{CI}$ $1.001-1.010 ; \mathrm{P}=0.019)$, and DDI (OR $=1.001 ; 95 \%$ CI 1.000-1.001; $\mathrm{P}=0.010)$ were independent predictors of high PCI (Table 2).

ROC analysis showed that the AUCs for discriminating patients with high PCI from those with low PCI according to the NLR, PLR, and DDI were 0.738 , 0.664 , and 0.800 , respectively (Figure $2 \mathrm{~A}-\mathrm{C}$ ). The cutoff values for the NLR, PLR, and DDI were set at 2.7236, 246.6863, and 545, respectively. The sensitivity and specificity were 0.886 and 0.507 , respectively, for the NLR; 0.486 and 0.791 , respectively, for the PLR; and 0.686 and 0.806 , respectively, for the DDI. This binary system was used to determine the NPD score.

\section{Relationship Between PCl and NPD Score}

The NPD score ranged from 0 to 3 . The patients were assigned one point if NLR was $>2.7236$, PLR was $>$ 246.6863 , or DDI was $>545$. The NPD score was calculated by summing up these points. NPD scores of $0,1,2$, and 3 were obtained for 31 (30.4\%), 25 (24.5\%), 30 $(29.4 \%)$, and $16(15.7 \%)$ patients, respectively. This score was significantly higher for patients with high PCI than for those with low PCI $(\mathrm{P}=0.001)$ (Table 3$)$. ROC analysis showed that the AUCs for discriminating patients with high PCI from those with low PCI according to the NPD score were 0.797 (Figure 3). 
Table I Characteristics of the Low and High PCl Groups

\begin{tabular}{|c|c|c|c|c|c|}
\hline Variable & Low PCI $(n=67)$ & $95 \% \mathrm{Cl}$ & High PCI $(n=35)$ & $95 \% \mathrm{Cl}$ & P-value \\
\hline Gender & & & & & 0.715 \\
\hline Male & 37 & & 18 & & \\
\hline Female & 30 & & 17 & & \\
\hline Age & $57.1 \pm 13.2$ & $53.9-60.3$ & $58.7 \pm 9.9$ & $55.1-62.0$ & 0.547 \\
\hline Smoking history & & & & & 0.377 \\
\hline Yes & 25 & & 10 & & \\
\hline No & 42 & & 25 & & \\
\hline Alcohol consumption & & & & & 0.878 \\
\hline Yes & 24 & & 12 & & \\
\hline No & 43 & & 23 & & \\
\hline BMI & $21.8 \pm 2.8$ & $21.1-22.5$ & $21.5 \pm 2.6$ & $20.6-22.4$ & 0.496 \\
\hline \multicolumn{6}{|l|}{ Tumor location } \\
\hline Upper & II & & 2 & & 0.242 \\
\hline Middle & 25 & & 15 & & \\
\hline Lower & 31 & & 16 & & \\
\hline \multicolumn{6}{|l|}{ Differentiation } \\
\hline Moderate & 13 & & 3 & & 0.500 \\
\hline Poor & 39 & & 18 & & \\
\hline Unknown & 15 & & 14 & & \\
\hline $\mathrm{Hb}$ & $|2.0 \pm 2| .0$ & $10.3-20.6$ & $|2.8 \pm 2| .5$ & $8.3-23,1$ & 0.958 \\
\hline ALB & $40.4 \pm 5.19$ & $38.1-40.6$ & $38.8 \pm 5.15$ & $36.4-39.9$ & 0.264 \\
\hline NLR & $2.72 \pm 2.45$ & $2.77-3.97$ & $4.33 \pm 5.52$ & $3.99-7.78$ & 0.001 \\
\hline PLR & $187.3 \pm 90.5$ & $175.52-219.68$ & $236.0 \pm 163.1$ & $219.44-331.47$ & 0.007 \\
\hline DDI & $237.0 \pm 733.3$ & $294.4 I-652.15$ & $779.0 \pm 1212.6$ & $797.81-1630.88$ & 0.001 \\
\hline CEA & $2.48 \pm 80.4$ & $6.9-52.8$ & $2.05 \pm 11.6$ & $2.0-10.2$ & 0.209 \\
\hline $\mathrm{CA} 125$ & $35.3 \pm 170.6$ & $36.6-119.8$ & $134.0 \pm 154.5$ & $122.6-232.0$ & 0.001 \\
\hline CA199 & $28.5 \pm 2526.6$ & $450.9-1948.2$ & $19.1 \pm 1846.6$ & $-121.7-1505.3$ & 0.356 \\
\hline AFP & $2.19 \pm 836.1$ & $-125.2-385.3$ & $2.6 \mathrm{I} \pm 6.3$ & $1.3-6.7$ & 0.310 \\
\hline
\end{tabular}

\section{Relationship Between Prognosis and NPD Score}

The median survival times (MSTs) for patients with NPD scores of $0,1,2$, and 3 were 26.9, 23.9, 13.4, and 12.9 months, respectively (Table 4 ). The overall difference in the MST according to the NPD score was significant $(\mathrm{P}=$ $0.027)$. The patients were divided into high-risk and lowrisk groups based on their NPD scores ( $<2$ and $\geq 2$, respectively). The MSTs of the two groups were 25.6 months (95\% CI 20.5-30.8) and 14.2 months (95\% CI 9.7-18.8), respectively. The Kaplan-Meier survival curves determined based on the NPD score demonstrated that survival was significantly worse among patients with a high NPD score than among those with a low score $(P=0.003)$ (Figure 4).

Univariate analysis showed that PCI and NPD scores $\geq 2$ can be used to determine the patient prognosis, while gender, age, BMI, differentiation, and serum levels of
CEA, CA199, CA125, and AFP had no marked impact on the survival. Multivariate analysis revealed that PCI $(\mathrm{HR}=1.062,95 \% \mathrm{CI} 1.020-1.105 ; \mathrm{P}=0.003)$ and NPD scores $\geq 2(\mathrm{HR}=2.322 ; 95 \%$ CI $1.234-4.369 ; \mathrm{P}=0.009)$ are independent predictors of the overall survival (OS) (Table 5).

The patient received a second laparoscopic exploration after HIPEC and 4 cycles of neoadjuvant systemic chemotherapy if the initial PCI $\leq 20$. 41 patients (40.2\%) underwent a second laparoscopic exploration (Figure 5). The PCI level decreased or remained unchanged for 36 patients $(87.8 \%)$ and increased for five patients. The average PCI was $5.17 \pm 9.44$ (range 0-39), and the difference between the initial and subsequent PCI levels was statistically significant $(\mathrm{P}<0.05)$. Among the 41 patients, cytoreductive surgery (CRS) was performed for 29 (70.7\%), including resection of the primary tumor with acceptable margins, 
Table 2 Independent Predictors of High PCI

\begin{tabular}{|c|c|c|c|c|}
\hline \multirow[t]{2}{*}{ Variable } & \multicolumn{2}{|l|}{ Univariate } & \multicolumn{2}{|l|}{ Multivariate } \\
\hline & OR (95\% CI) & $P$-value & OR (95\% CI) & $P$-value \\
\hline \multicolumn{5}{|l|}{ Gender } \\
\hline Male & Ref & & - & \\
\hline Female & I.165 (0.5I3-2.643) & 0.715 & - & - \\
\hline \multicolumn{5}{|l|}{ Age } \\
\hline$<70$ & Ref & & - & \\
\hline$\geq 70$ & $0.764(0.246-2.375)$ & 0.642 & - & - \\
\hline BMI & $0.960(0.830-1.122)$ & 0.643 & - & - \\
\hline \multicolumn{5}{|l|}{ Differentiation } \\
\hline Well and moderately & Ref & & Ref & \\
\hline Poorly & $0.551(0.295-1.030)$ & 0.062 & $0.604(0.29|-| .254)$ & 0.176 \\
\hline NLR & I.278 (I.048-I.558) & 0.015 & $1.276(1.051-1.550)$ & 0.014 \\
\hline PLR & $1.006(1.002-1.010)$ & 0.008 & $1.006(1.001-1.010)$ & 0.019 \\
\hline DDI & $1.000(0.998-1.002)$ & 0.002 & $1.001(1.000-1.001)$ & 0.010 \\
\hline CEA & $0.982(0.959-1.006)$ & 0.136 & - & - \\
\hline CA199 & $1.000(1.000-1.000)$ & 0.388 & - & - \\
\hline $\mathrm{CA} / 25$ & $1.005(1.00 \mathrm{I}-1.008)$ & 0.014 & $1.003(1.000-1.006)$ & 0.088 \\
\hline AFP & $1.000(0.997-1.002)$ & 0.666 & - & - \\
\hline
\end{tabular}

Abbreviations: DDI, D-dimer; NLR, neutrophil-to-lymphocyte ratio; PCl, peritoneal cancer index; PLR, platelet-lymphocyte ratio.

lymphadenectomy, and peritoneotomy that involved the removal of peritoneal surfaces involved in the tumor. The mean value of PCI decrease was $5.1 \pm 9.3$ (95\% CI 1.22-9.03). Based on the PCI decrease ( $<6$ or not) observed during the two laparoscopic explorations, the patients were divided into low-decrease $(\mathrm{n}=28)$ and high-decrease $(n=13)$ groups. The differentiation, and NPD decrease were comparable in both groups. The NPD score decreased for four patients $(14.3 \%)$ in the low-decrease group and for eight patients (61.5\%) in the high-decrease group; the difference was statistically significant $(\mathrm{P}=0.002)$ (Table 6).

Univariate analysis demonstrated that gender, age, CA125 proportion, and a decrease in the NPD score were associated with a large decrease in the PCI $(\geq 6)$, while BMI, differentiation, and weight loss had no marked impact. Multivariate analysis showed that NPD-score decrease $(\mathrm{OR}=10.439 ; 95 \%$ CI $1.445-75.425 ; \mathrm{P}=$
A

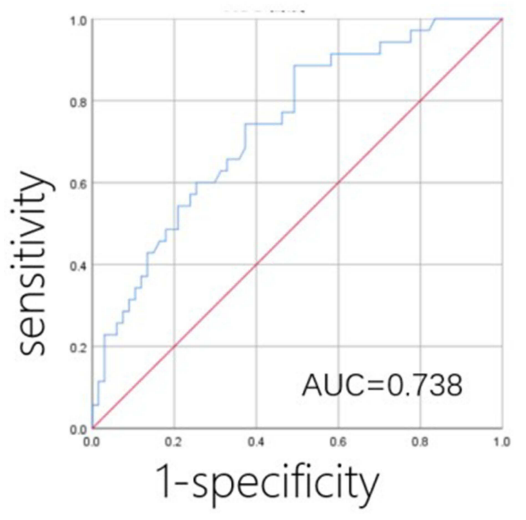

B

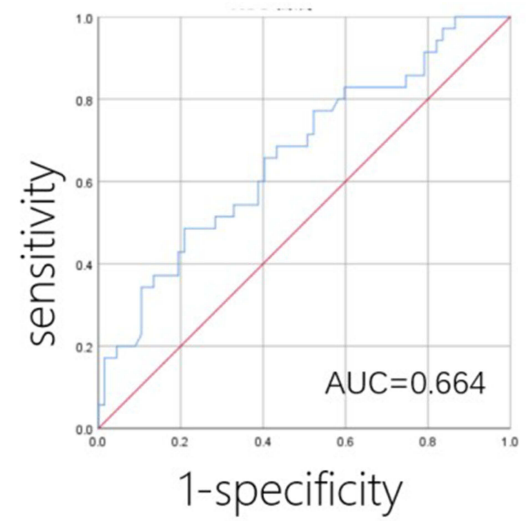

C

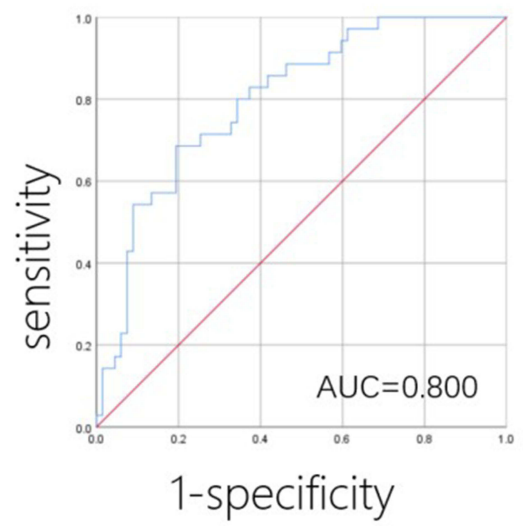

Figure 2 Receiver operating characteristic curves for discriminating patients with low $\mathrm{PCl}(<\mathrm{I5})$ and high $\mathrm{PCl}(\geq 15)$. (A) neutrophil-lymphocyte ratio, (B) plateletlymphocyte ratio, (C) D-dimer. 
Table 3 Relationship Between PCl and the NPD Score

\begin{tabular}{|l|l|l|l|l|l|l|}
\hline & \multicolumn{3}{|l|}{ NPD Score } & \multirow{2}{*}{ OR } & \multirow{2}{*}{ P-value } \\
\cline { 2 - 5 } & $\mathbf{0}$ & $\mathbf{1}$ & $\mathbf{2}$ & $\mathbf{3}$ & & \\
\hline $\begin{array}{l}\text { Low PCl } \\
\text { High PCl }\end{array}$ & 30 & 16 & 18 & 3 & & \\
\hline
\end{tabular}

Abbreviations: NPD, NLR-PLR-DDI; PCI, peritoneal cancer index.

0.020) is an independent predictor of PCI decrease (Table 7).

\section{Discussion}

Most previous studies evaluated NLR, PLR, and DDI individually as well as their clinical significance in patients with various malignant tumors, including gastric cancer. ${ }^{18-21}$ However, very few studies have reported the relationship between these markers and peritoneal metastasis of gastric cancer. The latter is often diagnosed late based on imaging findings or often during an invasive procedure such as laparoscopy or laparotomy. ${ }^{22} \mathrm{CT}$ has a sensitivity of only $11 \%$ and $25-50 \%$ for tumor nodules $<0.5$ and $1 \mathrm{~cm}$, respectively. ${ }^{23}$ Therefore, CT significantly underestimates the extent of disease in the peritoneal cavity. $^{23-25}$ In addition, DSL, an invasive procedure,

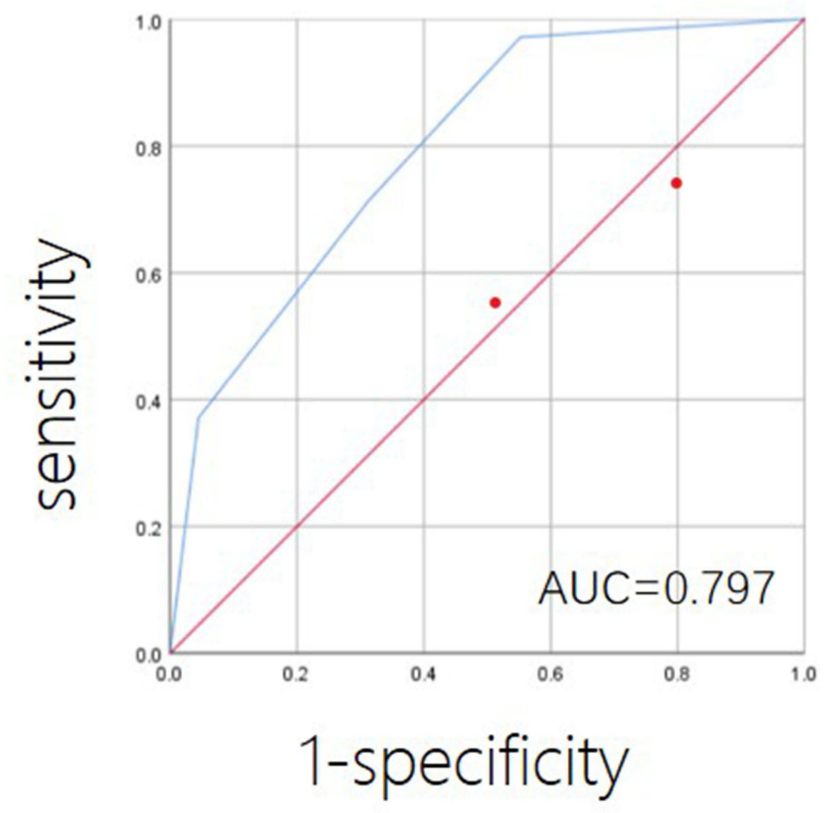

Figure 3 Receiver operating characteristic curves for discriminating patients with low $\mathrm{PCl}(<15)$ and high $\mathrm{PCl}(\geq 15)$ according to NPD score.
Table 4 Relationship Between Prognosis and the NPD Score

\begin{tabular}{|l|l|l|l|l|}
\hline NPD score & Mean & SD & $\mathbf{9 5 \%} \mathbf{C l}$ & P-value \\
\hline 0 & 26.887 & 3.044 & $20.92-32.85$ & 0.027 \\
$\mathrm{I}$ & 23.955 & 4.394 & $15.34-32.57$ & \\
2 & 13.417 & 2.595 & $8.33-18.50$ & \\
3 & 12.889 & 2.874 & $7.25-18.52$ & \\
\hline
\end{tabular}

Abbreviation: NPD, NLR-PLR-DDI.

has some limitations such as a high cost, inconvenience, and the need for general anesthesia. NLR, PLR, and DDI are calculated from existing routine lab procedures based on a routine peripheral blood draw. As these markers are inexpensive and readily available, they can be conveniently monitored overtime.

Neutrophils have been shown to impede the immune system and promote tumor growth by inhibiting the lymphocyte activity and T-cell response. ${ }^{26,27}$ Lymphocytes can cause cytotoxic cell death, produce inhibitory cytokines, and regulate the activity of tumor cells. Therefore, fewer lymphocytes may result in poor control of tumor proliferation. ${ }^{28}$ Platelets play an important role in tumor proliferation and metastasis. ${ }^{29}$ An association between elevated plasma-DDI levels and poor survival outcomes has been observed in various gastrointestinal carcinomas. $^{30-32}$ Recent studies have shown that cancer and the hemostatic system have a bidirectional effect. The potential mechanism for DDI elevation in malignancy might be associated with circulating tumor cell (CTC) clot formation (tumor thrombus). ${ }^{33-37}$

A systematic review and meta-analysis involving 100 studies and 40,559 patients with various solid malignancies

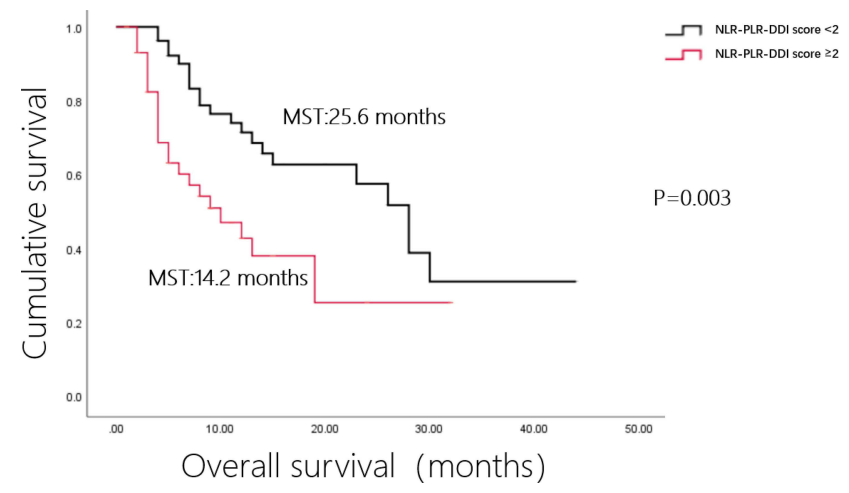

Figure 4 Kaplan-Meier survival curves according to the NPD score. 
Table 5 Univariate and Multivariate Analyses of Overall Survival

\begin{tabular}{|c|c|c|c|c|}
\hline \multirow[t]{2}{*}{ Variable } & \multicolumn{2}{|l|}{ Univariate } & \multicolumn{2}{|l|}{ Multivariate } \\
\hline & HR (95\% CI) & $P$-value & HR (95\% Cl) & $P$-value \\
\hline \multicolumn{5}{|l|}{ Gender } \\
\hline Male & Ref & & Ref & \\
\hline Female & $0.607(0.330-1.115)$ & 0.107 & $0.540(0.289-1.009$ & 0.053 \\
\hline \multicolumn{5}{|l|}{ Age } \\
\hline$<70$ & Ref & & Ref & \\
\hline$\geq 70$ & I.326 (0.6I2-2.87I) & 0.474 & - & - \\
\hline BMI & 0.927 (0.827-1.039) & 0.192 & $0.937(0.830-1.056)$ & 0.285 \\
\hline \multicolumn{5}{|l|}{ Differentiation } \\
\hline Well and moderately & Ref & & Ref & \\
\hline Poorly & $0.819(0.546-1.230)$ & 0.337 & $0.808(0.543-1.202)$ & 0.294 \\
\hline CEA & $0.996(0.984-1.009)$ & 0.563 & - & - \\
\hline CAI99 & $1.000(1.000-1.000)$ & 0.473 & - & - \\
\hline CAI25 & $1.000(0.998-1.002)$ & 0.838 & - & - \\
\hline AFP & $0.999(0.996-1.003)$ & 0.787 & - & - \\
\hline $\mathrm{PCl}$ & 1.051 (1.013-1.089) & 0.008 & $1.062(1.020-1.105)$ & 0.003 \\
\hline \multicolumn{5}{|l|}{ NPD score } \\
\hline$<2$ & Ref & & Ref & \\
\hline$\geq 2$ & $2.397(1.297-4.429)$ & 0.005 & $2.322(1.234-4.369)$ & 0.009 \\
\hline
\end{tabular}

Abbreviations: NPD, NLR-PLR-DDI; PCl, peritoneal cancer index.

concluded that a higher NLR is associated with worse OS. ${ }^{38}$ A meta-analysis of 20 studies and 12,754 patients showed that in patients with various solid tumors, higher PLR was associated with worse OS. ${ }^{39}$ Another meta-analysis of 30 studies and 5928 patients suggested that higher pretreatment plasma-DDI levels can be used to predict adverse survival outcomes among patients with different types of gastrointestinal carcinomas. ${ }^{16}$

The present study investigated the relationship between PCI and various laboratory test data. Hao et al reported that patients with PCI $<15$ and metastatic lymph nodes have a higher response rate and better prognosis after chemotherapy. ${ }^{17}$ Initially, we found NLR, PLR, and DDI to be independent predictors of high PCI in patients with peritoneal metastasis of gastric cancer. ROC analysis revealed the cut-off values for NLR, PLR, and DDI and we combined the NLR, PLR, and DDI to create the NPD score as a new scoring system for predicting PCI and prognosis in patients with peritoneal metastasis of gastric cancer. The results revealed that the NPD score is significantly higher in patients with high PCI than in those with low PCI.
We also evaluated the relationship between the NPD score and prognosis in the same population. KaplanMeier analysis showed that the MST was greater in patients with an NPD score of 0 or 1 than in those with an NPD score of 2 or 3 (25.6-14.2 months). Multivariate analysis revealed that PCI and NPD score $\geq 2$ were independent predictors of OS. The NPD score decreased after neoadjuvant systemic chemotherapy and HIPEC and became an independent predictor of the PCI decrease.

The following factors can explain our findings. First, chronic inflammation may result in the recruitment of leukocytes from the peripheral circulatory system to the tumor tissue. ${ }^{40}$ Consequently, transcription factors such as nuclear factor-k-gene binding $(\mathrm{NF}-\kappa \mathrm{B})$ and signal transducer and activator of transcription 3 (STAT3) in inflammatory and tumor cells become activated and promote the production of inflammatory mediators, including chemokines and cytokines. ${ }^{41}$ Neutrophils release vascular endothelial growth factors through degranulation, resulting in tumor growth. ${ }^{42}$ Second, lymphopenia results in an immunosuppressive state, which is present in most patients with advanced 


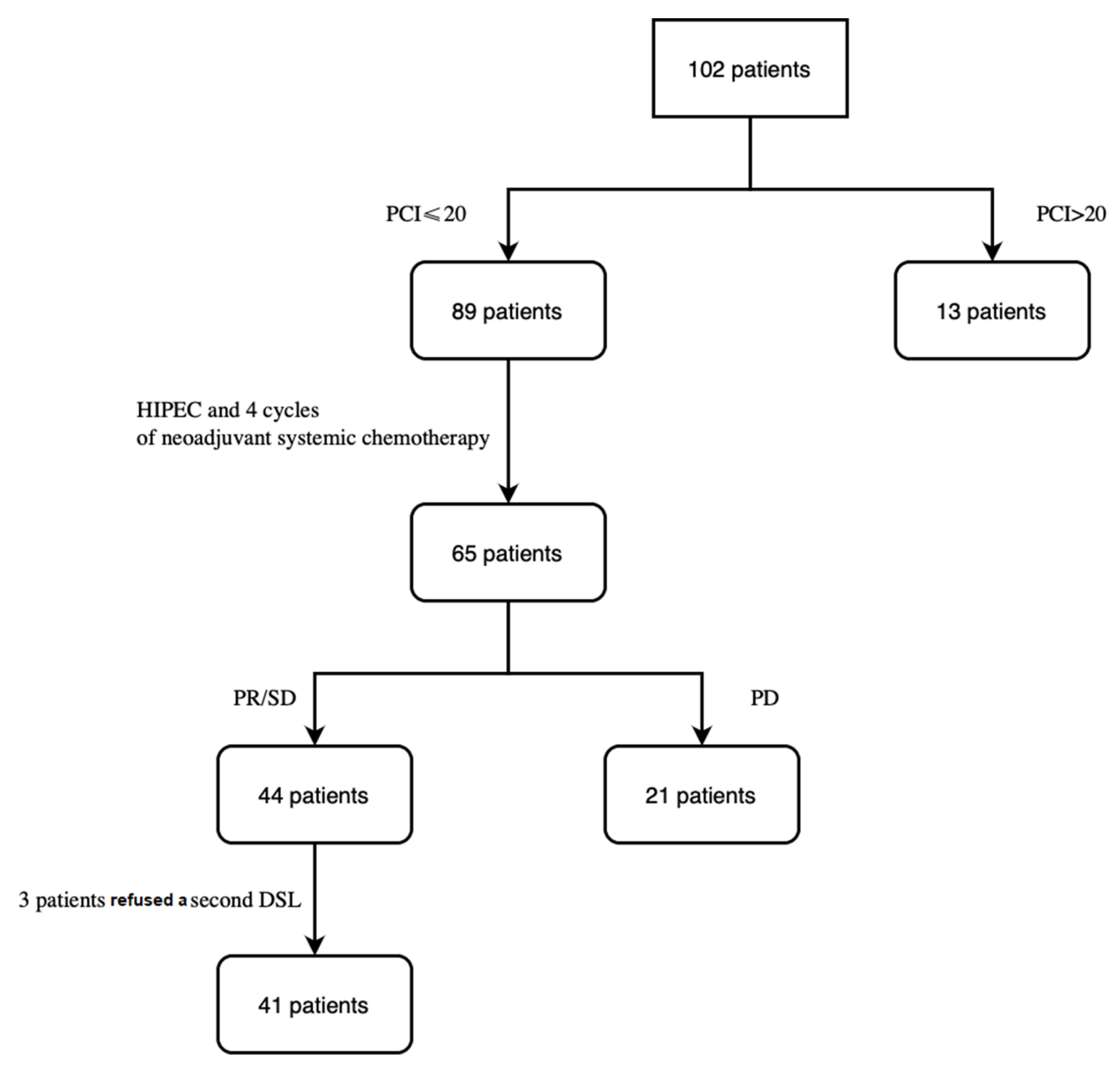

Figure $\mathbf{5}$ Flow-chart with the exclusion criteria for DSL.

cancer. ${ }^{43}$ This may be due to the increased sensitivity of lymphocyte $\mathrm{T}$ cells to apoptosis, resulting in the upregulation of death receptors and a chronic activation state, ${ }^{44}$ which, in turn, reduces the immune response activity of tumor antigens released by cancer cells during chemotherapy. ${ }^{45}$ Third, platelets — the main component of peripheral blood - can secrete inflammatory mediators and growth factors such as vascular endothelial growth factor (VEGF), which can stimulate tumor angiogenesis, growth, and metastasis. ${ }^{46}$ Fourth, the potential mechanism of DDI elevation in malignant tumors may be related to CTC clot formation (tumor thrombus). Tumor thrombus participates in the metastasis process by protecting cancer cells from damage caused by the immune system, reducing the stress resulting from blood flow, promoting the adherence of tumor cells to the vascular wall, and promoting vascular extravasation or angiogenesis, or by promoting endothelial cell retraction. ${ }^{34,35}$ These results suggest that the NPD scoring system can serve as a useful predictor for PCI before DSL. It is also a prognostic factor for patients with peritoneal metastasis from gastric cancer. Finally, it is inexpensive, convenient, and noninvasive.

The present study has several limitations as well. First, it is a retrospective and nonrandomized study. Therefore, the potential for bias cannot be completely excluded, although multivariate analysis was performed to minimize the effect of confounding factors. Secondly, PCI is a somewhat arbitrary method for determining the tumor load. It is assessed by surgeons and does not measure the actual volume of the tumor. 
Table 6 Characteristics of PCI Decrease $<6$ Group and $\geq 6$ Group

\begin{tabular}{|c|c|c|c|}
\hline \multirow[t]{2}{*}{ Variable } & \multicolumn{2}{|c|}{ PCI Decrease } & \multirow[t]{2}{*}{ P-value } \\
\hline & $<6(n=28)$ & $\geq 6(n=13)$ & \\
\hline Gender & & & 0.025 \\
\hline Male & 17 & 3 & \\
\hline Female & 11 & 10 & \\
\hline Age & $57.8 \pm 11.3$ & $44.3 \pm 9.1$ & 0.479 \\
\hline BMI & $21.2 \pm 3.1$ & $21.0 \pm 2.3$ & 0.327 \\
\hline Tumor location & & & 0.469 \\
\hline Upper & 4 & I & \\
\hline Middle & 12 & 7 & \\
\hline Lower & 12 & 5 & \\
\hline \multicolumn{4}{|l|}{ Differentiation } \\
\hline Moderately & 5 & 2 & 0.248 \\
\hline Poorly & 15 & 9 & \\
\hline Unknown & 8 & 2 & \\
\hline NPD score decrease & & & 0.002 \\
\hline$\leq 0$ & 24 & 5 & \\
\hline$>0$ & 4 & 8 & \\
\hline CAI 25 proportion & $2.26 \pm 2.53$ & $9.61 \pm 8.37$ & 0.001 \\
\hline
\end{tabular}

Table 7 Univariate and Multivariate Analysis of PCI Decrease

\begin{tabular}{|c|c|c|c|c|}
\hline \multirow[t]{2}{*}{ Variable } & \multicolumn{2}{|l|}{ Univariate } & \multicolumn{2}{|l|}{ Multivariate } \\
\hline & OR $(95 \% \mathrm{CI})$ & P-value & OR $(95 \% \mathrm{CI})$ & P-value \\
\hline \multicolumn{5}{|l|}{ Gender } \\
\hline Male & Ref & & Ref & \\
\hline Female & $5.152(1.153-23.000)$ & 0.032 & $0.733(0.052-10.352)$ & 0.818 \\
\hline \multicolumn{5}{|l|}{ Age } \\
\hline$<70$ & Ref & & Ref & \\
\hline$\geq 70$ & $0.893(0.828-0.964)$ & 0.004 & $0.895(0.782-1.025)$ & 0.108 \\
\hline BMI & $0.982(0.776-1.243)$ & 0.879 & $0.937(0.830-1.056)$ & 0.285 \\
\hline \multicolumn{5}{|l|}{ Differentiation } \\
\hline Well and moderately & Ref & & Ref & \\
\hline Poorly & $1.458(0.565-3.758)$ & 0.435 & - & - \\
\hline CAI25 proportion & $1.349(1.092-1.666)$ & 0.005 & $1.293(0.985-1.732)$ & 0.085 \\
\hline Weight loss & $1.130(0.939-1.359)$ & 0.196 & I. 197 (0.908-1.578) & 0.201 \\
\hline NPD score decrease & $9.6(2.060-44.74 I)$ & 0.004 & $10.439(1.445-75.425)$ & 0.020 \\
\hline
\end{tabular}

\section{Conclusions}

We demonstrated that the NPD score is a useful blood marker for predicting PCI and survival outcomes in patients with peritoneal metastasis of gastric cancer. In the near future, we believe that the NPD scoring system can be used as a key indicator for the clinical treatment of patients with gastric cancer and peritoneal cancer and help in formulating treatment strategies.

\section{Data Sharing Statement}

The data and materials of the current study are available.

\section{Ethics Approval and Consent to Participate}

This study was conducted in accordance with the Declaration of Helsinki and was approved by the Ethics Committee of The Cancer Hospital of the University of 
Chinese Academy of Sciences (Zhejiang Cancer Hospital) (ethics number: IRB-2015-170), and all the subjects or their families received informed consent.

\section{Acknowledgments}

We thank all study participants and research staff who participated in this work.

\section{Author Contributions}

All authors made a significant contribution to the work reported, whether that is in the conception, study design, execution, acquisition of data, analysis and interpretation, or in all these areas; took part in drafting, revising or critically reviewing the article; gave final approval of the version to be published; have agreed on the journal to which the article has been submitted; and agree to be accountable for all aspects of the work.

\section{Funding}

This study was supported by the Public Service Technology Application Research Project of Science and Technology Department of Zhejiang Province (GF21H160035), the Project of Administration of Traditional Chinese Medicine of Zhejiang Province of China (2020ZA020) and Medical Health Science and Technology Project of Zhejiang Provincial Health Commission (2020KY471, 2017KY251).

\section{Disclosure}

The authors declare that they have no conflict of interest.

\section{References}

1. Ferlay J, Soerjomataram I, Dikshit R, et al. Cancer incidence and mortality worldwide: sources, methods and major patterns in GLOBOCAN 2012. Int $J$ Cancer. 2015;136(5):E359-386. doi:10. 1002/ijc. 29210

2. Montori G, Coccolini F, Ceresoli M, et al. The treatment of peritoneal carcinomatosis in advanced gastric cancer: state of the art. Int J Surg Oncol. 2014;2014:912418. doi:10.1155/2014/912418

3. Coccolini F, Montori G, Ceresoli M, et al. Advanced gastric cancer: what we know and what we still have to learn. World J Gastroenterol. 2016;22(3):1139-1159.

4. Geng X, Liu H, Lin T, et al. Survival benefit of gastrectomy for gastric cancer with peritoneal carcinomatosis: a propensity score-matched analysis. Cancer Med. 2016;5(10):2781-2791.

5. Yonemura Y, Canbay E, Endou Y, et al. Peritoneal cancer treatment. Expert Opin Pharmacother. 2014;15(5):623-636.

6. Elias D, Goere D, Dumont F, et al. Role of hyperthermic intraoperative peritoneal chemotherapy in the management of peritoneal metastases. Eur J Cancer. 2014;50(2):332-340.
7. Tabrizian P, Shrager B, Jibara G, et al. Cytoreductive surgery and hyperthermic intraperitoneal chemotherapy for peritoneal carcinomatosis: outcomes from a single tertiary institution. J Gastrointest Surg. 2014;18(5):1024-1031.

8. Diakos CI, Charles KA, McMillan DC, Clarke SJ. Cancer-related inflammation and treatment effectiveness. Lancet Oncol. 2014;15 (11): $493-503$.

9. Roxburgh CS, McMillan DC. Cancer and systemic inflammation: treat the tumour and treat the host. Br J Cancer. 2014;110 (6): 1409-1412.

10. Mascarella MA, Mannard E, Silva SD, Zeitouni A. Neutrophil-tolymphocyte ratio in head and neck cancer prognosis: a systematic review and meta-analysis. Head Neck. 2018;40(5):1091-1100. doi:10.1002/hed.25075

11. Takenaka Y, Oya R, Kitamiura $T$, et al. Platelet count and platelet-lymphocyte ratio as prognostic markers for head and neck squamous cell carcinoma: meta-analysis. Head Neck. 2018;40 (12):2714-2723. doi:10.1002/hed.25366

12. Arigami T, Okumura H, Matsumoto M, et al. Analysis of the fibrinogen and neutrophil-lymphocyte ratio in esophageal squamous cell carcinoma: a promising blood marker of tumor progression and prognosis. Medicine. 2015;94(42):e1702. doi:10.1097/MD.0000000000001702

13. Arigami T, Uenosono Y, Matsushita D, et al. Combined fibrinogen concentration and neutrophil-lymphocyte ratio as a prognostic marker of gastric cancer. Oncol Lett. 2016;11(2):1537-1544. doi:10.3892/ ol.2015.4049

14. Liu L, Zhang X, Yan B, et al. Elevated plasma D-dimer levels correlate with long term survival of gastric cancer patients. PLoS One. 2014;9(3):e90547. doi:10.1371/journal.pone.0090547

15. Ay C, Dunkler D, Pirker R, et al. High D-dimer levels are associated with poor prognosis in cancer patients. Haematologica. 2012;97 (8):1158-1164. doi:10.3324/haematol.2011.054718

16. Rong G, Fan W, Shen J. High pretreatment plasma D-dimer levels predict poor prognosis in gastrointestinal cancers: a meta-analysis. Medicine. 2019;98(29):e16520. doi:10.1097/MD.0000000000016520

17. Hao Y, Liu Y, Ishibashi H, Wakama S, Nishino E, Yonemura Y. Downstaging of lymph node metastasis after neoadjuvant intraperitoneal and systemic chemotherapy in gastric carcinoma with peritoneal metastasis. Eur J Surg Oncol. 2019;45(8):1493-1497. doi:10.1016/j.ejso.2019.03.011

18. Koh CH, Bhoo-Pathy N, Ng KL, et al. Utility of pre-treatment neutrophil-lymphocyte ratio and platelet-lymphocyte ratio as prognostic factors in breast cancer. Br J Cancer. 2015;113(1):150-158. doi:10.1038/bjc.2015.183

19. Chan JC, Chan DL, Diakos CI, et al. The lymphocyte-to-monocyte ratio is a superior predictor of overall survival in comparison to established biomarkers of resectable colorectal cancer. Ann Surg. 2017;265(3):539-546. doi:10.1097/SLA.0000000000001743

20. Sierzega M, Lenart M, Rutkowska $M$, et al. Preoperative neutrophil-lymphocyte and lymphocyte-monocyte ratios reflect immune cell population rearrangement in resectable pancreatic cancer. Ann Surg Oncol. 2017;24(3):808-815. doi:10.1245/s10434016-5634-0

21. Nakamura K, Nakayama K, Ishikawa M, et al. High pre-treatment plasma d-dimer level as a potential prognostic biomarker for cervical carcinoma. Anticancer Res. 2016;36(6):2933-2938.

22. McMullen JRW, Selleck M, Wall NR, Senthil M. Peritoneal carcinomatosis: limits of diagnosis and the case for liquid biopsy. Oncotarget. 2017;8 (26):43481-43490. doi:10.18632/oncotarget.16480

23. Koh JL, Yan TD, Glenn D, Morris DL. Evaluation of preoperative computed tomography in estimating peritoneal cancer index in colorectal peritoneal carcinomatosis. Ann Surg Oncol. 2009;16 (2):327-333. doi:10.1245/s10434-008-0234-2 
24. Low RN, Barone RM, Lucero J. Comparison of MRI and CT for predicting the Peritoneal Cancer Index (PCI) preoperatively in patients being considered for cytoreductive surgical procedures. Ann Surg Oncol. 2015;22(5):1708-1715. doi:10.1245/s10434-014-4041-7

25. Esquivel J, Chua TC, Stojadinovic A, et al. Accuracy and clinical relevance of computed tomography scan interpretation of peritoneal cancer index in colorectal cancer peritoneal carcinomatosis: a multi-institutional study. J Surg Oncol. 2010;102(6):565-570. doi: $10.1002 /$ jso. 21601

26. De Larco JE, Wuertz BR, Furcht LT. The potential role of neutrophils in promoting the metastatic phenotype of tumors releasing interleukin-8. Clin Cancer Res. 2004;10(15):4895-4900.

27. el-Hag A, Clark RA. Immunosuppression by activated human neutrophils. Dependence on the myeloperoxidase system. J Immunol. 1987;139(7):2406-2413.

28. Li X, An B, Zhao Q, et al. Combined fibrinogen and neutrophil-lymphocyte ratio as a predictive factor in resectable colorectal adenocarcinoma. Cancer Manag Res. 2018;10:6285-6294.

29. Chen L, Hao Y, Cong X, et al. Peripheral venous blood Platelet-toLymphocyte Ratio (PLR) for predicting the survival of patients with gastric cancer treated with SOX or XELOX regimen neoadjuvant chemotherapy. Technol Cancer Res Treat. 2019;18:153303381982 9485.

30. Hong T, Shen D, Chen X, Wu X, Hua D. Preoperative plasma fibrinogen, but not D-dimer might represent a prognostic factor in non-metastatic colorectal cancer: a prospective cohort study. Cancer Biomark. 2017;19(1):103-111.

31. Diao D, Cheng Y, Song Y, Zhang H, Zhou Z, Dang C. D-dimer is an essential accompaniment of circulating tumor cells in gastric cancer. BMC Cancer. 2017;17(1):56.

32. Liu DQ, Li FF, Jia WH. Cumulative scores based on plasma D-dimer and serum albumin levels predict survival in esophageal squamous cell carcinoma patients treated with transthoracic esophagectomy. Chin J Cancer. 2016;35:11.

33. Im JH, Fu W, Wang $\mathrm{H}$, et al. Coagulation facilitates tumor cell spreading in the pulmonary vasculature during early metastatic colony formation. Cancer Res. 2004;64(23):8613-8619.

34. Horowitz NA, Blevins EA, Miller WM, et al. Thrombomodulin is a determinant of metastasis through a mechanism linked to the thrombin binding domain but not the lectin-like domain. Blood. 2011;118(10):2889-2895.
35. Labelle M, Begum S, Hynes RO. Direct signaling between platelets and cancer cells induces an epithelial-mesenchymal-like transition and promotes metastasis. Cancer Cell. 2011;20(5):576-590.

36. van den Berg YW, Osanto S, Reitsma PH, Versteeg HH. The relationship between tissue factor and cancer progression: insights from bench and bedside. Blood. 2012;119(4):924-932.

37. Zhang W, Dang S, Hong T, et al. A humanized single-chain antibody against beta 3 integrin inhibits pulmonary metastasis by preferentially fragmenting activated platelets in the tumor microenvironment. Blood. 2012;120(14):2889-2898.

38. Templeton AJ, McNamara MG, Šeruga B, et al. Prognostic role of neutrophil-to-lymphocyte ratio in solid tumors: a systematic review and meta-analysis. J Natl Cancer Inst. 2014;106(6):dju124.

39. Templeton AJ, Ace O, McNamara MG, et al. Prognostic role of platelet to lymphocyte ratio in solid tumors: a systematic review and meta-analysis. Cancer Epidemiol Biomarkers Prev. 2014;23 (7):1204-1212.

40. Coussens LM, Werb Z. Inflammation and cancer. Nature. 2002;420 (6917):860-867.

41. Colotta F, Allavena P, Sica A, Garlanda C, Mantovani A. Cancerrelated inflammation, the seventh hallmark of cancer: links to genetic instability. Carcinogenesis. 2009;30(7):1073-1081.

42. McCourt M, Wang JH, Sookhai S, Redmond HP. Proinflammatory mediators stimulate neutrophil-directed angiogenesis. Arch Surg. 1999;134(12):1325-1331; discussion 1331-1322.

43. Chua W, Charles KA, Baracos VE, Clarke SJ. Neutrophil/lymphocyte ratio predicts chemotherapy outcomes in patients with advanced colorectal cancer. Br J Cancer. 2011;104(8):1288-1295.

44. Dworacki G, Meidenbauer N, Kuss I, et al. Decreased zeta chain expression and apoptosis in CD3+ peripheral blood T lymphocytes of patients with melanoma. Clin Cancer Res. 2001;7(3Suppl):947s957s.

45. Apetoh L, Ghiringhelli F, Tesniere A, et al. Toll-like receptor 4-dependent contribution of the immune system to anticancer chemotherapy and radiotherapy. Nat Med. 2007;13(9):1050-1059.

46. Kusumanto YH, Dam WA, Hospers GA, Meijer C, Mulder NH. Platelets and granulocytes, in particular the neutrophils, form important compartments for circulating vascular endothelial growth factor. Angiogenesis. 2003;6(4):283-287.

\section{Publish your work in this journal}

Cancer Management and Research is an international, peer-reviewed open access journal focusing on cancer research and the optimal use of preventative and integrated treatment interventions to achieve improved outcomes, enhanced survival and quality of life for the cancer patient.
The manuscript management system is completely online and includes a very quick and fair peer-review system, which is all easy to use. Visit http://www.dovepress.com/testimonials.php to read real quotes from published authors. 